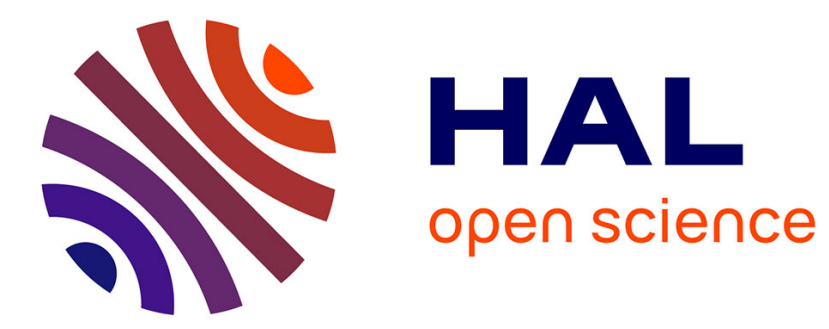

\title{
DYNAMIC BEHAVIOR OF ELASTOHYDRODYNAMIC LUBRICANTS IN SHEARING AND COMPRESSION
}

R. Feng, K. Ramesh

\section{> To cite this version:}

R. Feng, K. Ramesh. DYNAMIC BEHAVIOR OF ELASTOHYDRODYNAMIC LUBRICANTS IN SHEARING AND COMPRESSION. Journal de Physique IV Proceedings, 1991, 01 (C3), pp.C3-69C3-76. 10.1051/jp4:1991309 . jpa-00249900

HAL Id: jpa-00249900 https://hal.science/jpa-00249900

Submitted on 1 Jan 1991

HAL is a multi-disciplinary open access archive for the deposit and dissemination of scientific research documents, whether they are published or not. The documents may come from teaching and research institutions in France or abroad, or from public or private research centers.
L'archive ouverte pluridisciplinaire HAL, est destinée au dépôt et à la diffusion de documents scientifiques de niveau recherche, publiés ou non, émanant des établissements d'enseignement et de recherche français ou étrangers, des laboratoires publics ou privés. 


\title{
DYNAMIC BEHAVIOR OF ELASTOHYDRODYNAMIC LUBRICANTS IN SHEARING AND COMPRESSION
}

\author{
R. FENG and K.T. RAMESH \\ Department of Mechanical Engineering, The Johns Hopkins \\ University, Baltimore, MD 21218, U.S.A
}

\begin{abstract}
An experimental investigation has been conducted into the response of elastohydrodynamic (EHD) lubricants subjected to the high shear rates and pressures encountered in EHD lubrication and over comparable time scales. New techniques have been developed to measure the dynamic compressibility of EHD lubricants at pressures as high as 1 $G P a$, and the response to dynamic shearing at shear rates as high as $4.0 \times 10^{4} \sec ^{-1}$, over timescales of about $10^{-4} \mathrm{sec}$, and for a range of initial temperatures.
\end{abstract}

\section{Introduction}

Lubricants are subjected to pressures of several $G P a$ and to shearing at shear-rates of $10^{3}$ to $10^{5} \mathrm{sec}^{-1}$ within typical elastohydrodynamic (EHD) contacts ${ }^{[1]}$; the total time over which the lubricant is within the contact is of the order of $10^{-4} \mathrm{sec}$. The response of EHD lubricants under these conditions is of interest in the development of improved models of EHD contacts and elastohydrodynamic lubrication (EHL).

\section{Background}

At room temperature, atmospheric pressure and at low shear rates, most EHD lubricants behave as Newtonian liquids:

$$
\tau=\eta \dot{\gamma}
$$

where $\eta$, the viscosity, is a strong function of both the pressure and the temperature. However, at the pressures and temperatures that occur in typical EHD contacts, the lubricant is likely to be in the glassy state $^{[2]}$.

At small stresses and small strains, glassy lubricants exhibit a high-frequency elastic shear modulus in shear wave experiments using ultrasonics ${ }^{[3]}$. Under high pressures and at high shear-rates, however, the shear response of an EHD lubricant is believed to resemble that of an elastic/viscoplastic solid. Such a shear response has been characterized by a "limiting shear stress" which is strongly dependent on the pressure and temperature but is almost independent of the strain and strain-rate (particularly at high rates) ${ }^{[4-10]}$. The overall picture that arises from these observations is represented by the following relationship:

$$
\tau=\tau_{0}+\alpha p
$$


where $\tau_{0}$ is a constant (sometimes called the Eyring stress), and $\alpha$ is a proportionality constant. It has been suggested ${ }^{[11]}$ that limiting shear stress behavior is not necessarily limited to the glassy solid, but can be observed at sufficiently high shear rates even for lubricants in the liquid state.

An interesting aspect of the rheology of EHD lubricants is the effect of the time within the EHD contact on the response (a phenomenon known as "structural relaxation"). In general terms, one would expect that for early times the shear strength of the materials would be a function of the time under pressure, based on the idea that there is a certain minimum time required for the molecules of the lubricant to rearrange themselves into a new equilibrium arrangement corresponding to a change in the pressure. However, a comparison of the data presented in $[9,8,4]$ indicates structural relaxation in shearing is not a significant effect at least on the synthetic lubricant 5P4E.

Until recently, it was unclear whether there was in fact an effect of the time under pressure on the compressibility. Although an understanding of lubricant dynamic compressibility is vital to a successful simulation of the EHD contact, there has been a dearth of pressure-volume information even for quasistatic pressures. Dowson \& Higginson ${ }^{[12]}$ provided a widely used empirical fit to the pressure-density relationship for a mineral oil up to a quasistatic pressure of $400 \mathrm{MPa}$. However, in typical EHD conditions the pressures can be several $G P a$ and the transit time through the contact is only $10^{-4} \mathrm{sec}$. Several investigators have attempted to measure compressibility under similar conditions. Hamrock et al.$^{[13]}$ measured the quasistatic compressibility of several fluids up to pressures of $2.2 \mathrm{GPa}$; Bezot et al ${ }^{[14]}$ measured the bulk moduli of some lubricants for quasistatic pressures up to $400 \mathrm{MPa}$; and Alsaad et al ${ }^{[15]}$ made quasistatic dilatometric measurements for pressures up to $600 \mathrm{MPa}$. Lubricant compressibility had not been measured at the timescales actually occurring in elastohydrodynamic lubrication, and we undertook that task. We developed a new technique, using a compression Kolsky bar, to measure lubricant pressure-volume behavior for pressures up to $1 \mathrm{GPa}$ and for times on the order of $10^{-4} \mathrm{sec}$.

\section{Dynamic Compressibility Measurements}

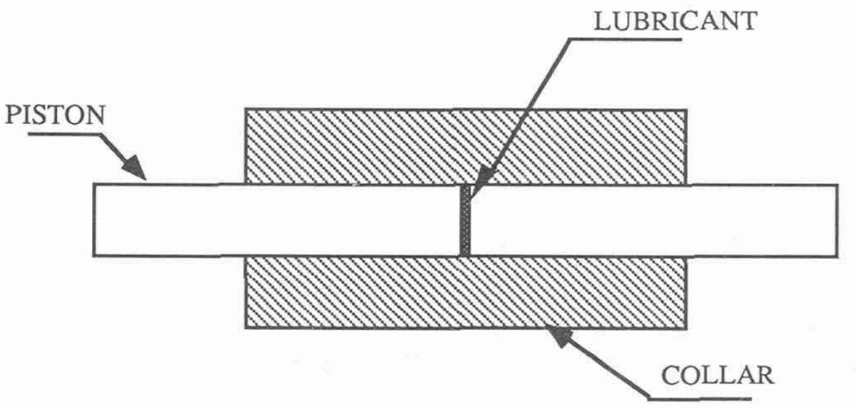

Fig. 1 The Lubricant Compressibility Specimen

The compression Kolsky bar is a device that consists of two long metal bars that sandwich a small cylindrical specimen. A compressive stress wave is generated in the input bar by projectile impact, and propagates down the bar into the specimen. This wave reverberates within the specimen, sending a transmitted wave into the output bar and a reflected wave back into the input bar. The bars are designed to remain elastic throughout the test, so that the complete displacement-time and stress-time histories at the specimen-bar interfaces can be determined from measurements (using strain gages) of the incident, 
reflected and transmitted pulses.

The specimen design (Fig. 1) uses two hard 4142 steel pistons moving within a heavy 4142 steel collar; the intent is to generate essentially uniaxial strain conditions. The pistons are impedance matched with the input and output bars. The clearance (generated by hand-lapping) between the pistons and the collar is such that a sliding motion is allowed, but no leakage of the lubricant occurs during the time of the experiment.

We assume that the change in the volume of the specimen due to elastic expansion in collar radius is negligible in comparison with that due to the axial compression. The error due to this assumption is easily computed, and is found to be less than $0.7 \%$. Then the volume ratio $V / V_{0}$ at time $\tau$ can be expressed in terms of the displacements in the axial direction:

$$
\frac{V}{V_{0}}=1-\frac{u_{1}(\tau)-u_{2}(\tau)}{h_{0}}
$$

where $h_{0}$ is the original thickness of the specimen.

The volume ratio is obtained in terms of the strain $\varepsilon_{R}$ in the reflected pulse $\mathrm{e}^{[16]}$ :

$$
\frac{V}{V_{0}}=1-\frac{2 c_{0}}{h_{0}} \int_{0}^{\tau} \varepsilon_{R} d t
$$

where $c_{0}$ is the velocity of longitudinal waves in the bars. Further, the state of stress in the specimen eventually becomes that of a hydrostatic pressure equal to the axial stress:

$$
P=\sigma_{\mathrm{s}}=E \varepsilon_{\mathrm{T}}
$$

Detailed justifications of these approximations may be found in [16].

Fig. 2 presents the results of our experiments on the compressibility of $5 \mathrm{P} 4 \mathrm{E}$ at room temperature $\left(30^{\circ} \mathrm{C}\right)$ along with the results of BARLOW et al.$^{[3]}$, and the dilatometric measurements of ALSAAD et al. ${ }^{[15]}$; these

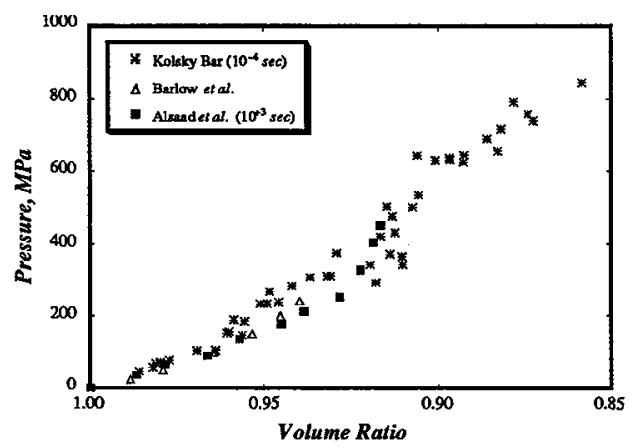

Fig. 2 The Effect of Time on Compressibility

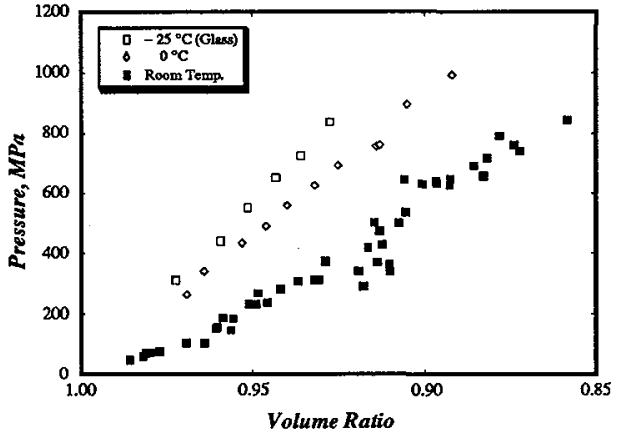

Fig. 3 Effect of Temp. on Compressibility

latter techniques correspond to essentially quasistatically applied pressures. BAIR \& WINER ${ }^{[17]}$ quote a time scale of $10^{3} \mathrm{sec}$ for the dilatometric measurements. It is apparent that the results of our compression Kolsky bar experiment are relatively close to those from the quasistatic measurements. The difference between the time scales of the dynamic and quasistatic experiments is of the order of $10^{7}$. We conclude that structural relaxation does not have a significant effect on the compressibility of this synthetic lubricant. 
Fig. 3 presents the results of measurements of the dynamic compressibility of the synthetic lubricant 5P4E at three different temperatures - room temperature, $0{ }^{\circ} \mathrm{C}$, and $-25^{\circ} \mathrm{C}$. It is apparent that the material becomes stiffer as the temperature is reduced, and that the pressure-volume behavior at low temperatures is almost linear. The dependence of the compressibility on the temperature is clearly significant, even for relatively small changes in temperature (approx. $50^{\circ} \mathrm{C}$ ); for fixed high pressure, the density does not appear to be linear with the change in temperature as is commonly assumed.

A comparison of the new data from the Kolsky bar experiment and the results of a full finite deformation simulation of plate impact experiments ${ }^{[16]}$ is presented in Fig. 4. The effective pressure/volume-ratio relation corresponding to the simulation is obtained as

$$
P=\frac{K\left\{1-\left(V / V_{0}\right)\right\}}{\left[1+a\left\{\left(V / V_{0}^{\prime}\right)-1\right\}\right]^{2}}
$$

where the pressure $P$ is positive; $K$ and $a$ are material constants. The relation (6), with constants obtained solely from simulation of the plate impact experiments, provides an excellent representation also of the (lower pressure) Kolsky bar data. Also shown in Fig. 4 is the widely used Dowson-Higginson relation ${ }^{[12]}$.

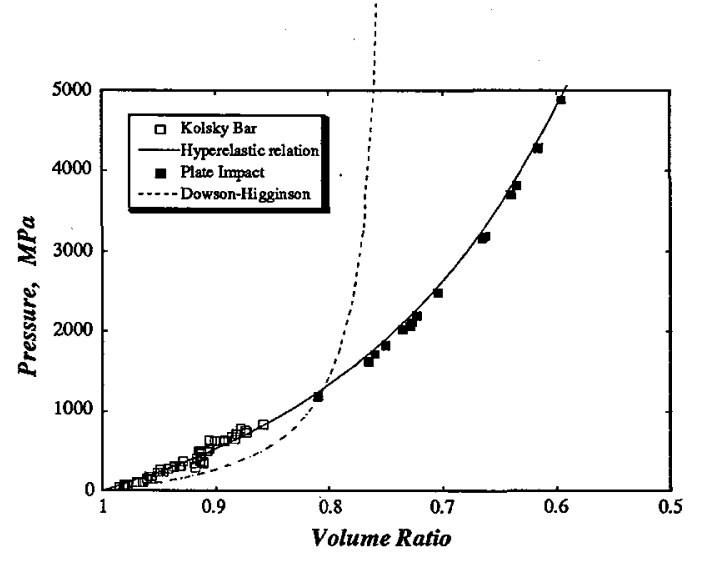

Fig. 4 Comparison of Models for Lubricant Compressibility

It is clear that this is not an appropriate pressure-density relation for this lubricant. In particular, the DowsonHigginson relation is seriously in error at high pressures, since it predicts that the lubricant cannot be compressed to less than $74 \%$ of its original volume.

\section{Conclusions from Compressibility Measurements}

- The compression Kolsky bar technique can be used to measure the dynamic compressibility of EHD lubricants under pressures and over timescales comparable to those encountered within the EHD contact.

- Comparison of our experimental results with those obtained by other techniques indicates that time under pressure does not have a significant effect on the compressibility of 5P4E for the time scales of elastohydrodynamic lubrication. Temperature, however, has a strong influence on the compressibility of this synthetic EHD lubricant. 
- It appears that the commonly used Dowson-Higginson relation is inappropriate for use in EHL simulations, particularly under extreme loading conditions. However, a pressure-volume relation of the form (6) is capable of describing the behavior of both lubricants over the entire range of pressures for which results are currently available.

\section{Dynamic Shearing}

This section describes the results of a technique (using a torsional Kolsky bar) developed to subject elastohydrodynamic lubricants to high-rate $\left(10^{3}-10^{4} \mathrm{sec}^{-1}\right)$ shearing deformations over time scales comparable to those actually observed in EHD lubrication. Dynamic shearing tests have been performed on the synthetic lubricant 5P4E and on the mineral oil HVI650. In the interests of space, however, we shall present only the results on 5P4E, in part because they are more complete.

The torsional Kolsky bar is a device used to subject small samples of comparatively soft materials to nearly homogeneous shearing deformations at high strain rates. The device consists of two long bars (designed to remain elastic throughout the test) that sandwich a short specimen. One end of the input bar carries a torquing device (a pulley driven by a hydraulic system). Both bars are instrumented with strain gages for measuring shear strain. The signals from the strain gages are processed through signal conditioners and then acquired using a high-precision, high-speed digital oscilloscope.

The lubricant is retained within a thin annular gap between two concentric cylinders. The outer cylinder is in fact an extension of the input bar (an aluminum tube, in this case), while the inner cylinder is an extension of the output bar, which is a precision steel shaft. The design is such that the only torque that can be transmitted from the input to the output bars is through the lubricant layer. The layer thickness used is 0.3 $\mathrm{mm}$, and the specimen length is typically $10 \mathrm{~mm}$.

In operation, a torque is applied to a short section (length $l$ ) of the input bar using the pulley; the rest of the input bar is restrained from rotation using a friction clamp. When the clamp is suddenly released a torsional pulse is generated that propagates down the input bar. The magnitude of the incident torsional pulse $T_{\mathrm{i}}$ is half the applied torque; the pulse duration depends on the length of the pre-torqued section, and the risetime $t_{\mathrm{r}}$ of the pulse depends on the speed of release of the friction clamp.

The torsional pulse propagates down the bar at the shear velocity $c_{2}$, arrives at the specimen, and is partly transmitted and partly reflected. After sufficient reverberations of the shear wave occur within the specimen, the specimen torque is spatially uniform and is equal to the transmitted torque $T_{t}$. Using the standard torsion equations, the stress sustained by the specimen can then be obtained in terms of the transmitted torque:

$$
\tau_{s}=\frac{2 T_{t}}{\pi D_{t}^{2} L_{s}}
$$

where $D_{t}$ is the diameter of the transmitted bar and $L_{s}$ is the specimen length. The specimen shear rate is controlled by the difference in angular velocities at the two specimen-bar interfaces and by the specimen geometry. For an elastic bar the torque in a pulse and the angular velocity are linearly related. Since the torques can be obtained from measurements of the incident, transmitted and reflected pulses, the shear rate within the specimen can also be determined:

$$
\dot{\gamma}_{s}=\frac{D_{s}\left(\omega_{1}-\omega_{2}\right)}{2 h}
$$

where $D_{s}$ is the specimen mean diameter, $h$ is the wall thickness, and $\omega_{1}$ and $\omega_{2}$ are the angular velocities 
on the two sides of the specimen. Thus the transmitted pulse directly gives the stress history of the specimen, while the reflected pulse provides a direct measure of the nominal shear rate within the sample.

\section{Results and Discussion}

A typical example of the shear rate history to which a lubricant is subjected (at $10^{\circ} \mathrm{C}$ ) is shown in Fig. 5 . The shear rate jumps to its final value over a time of perhaps $50 \mu \mathrm{sec}$ and remains essentially constant thereafter for a time of perhaps $250 \mu \mathrm{sec}$, after which unloading occurs. The risetime observed arises from the time involved in release of the torque by the clamp; during the early part of this risetime wave reverberations occur within the specimen and a homogeneous deformation should be developed. Shear rates in the range of $10^{3}-10^{4} \mathrm{sec}^{-1} \mathrm{can}$ be routinely obtained with the annular gap of $300 \mu \mathrm{m}$ that is used.

The history of the shear stress corresponding to the test shown in Fig. 5 is presented in Fig. 6. The shear stress appears to decrease during the test; this apparent softening behavior was first assumed to be a result of shear heating (an explanation proffered by Clyens $e t$ al.$^{[5]}$, who observed a similar behavior using a different specimen configuration). This apparent softening response is observed in every test, both for 5P4E and HVI650. The rate of softening is observed to increase with increasing applied (constant) shear rate at

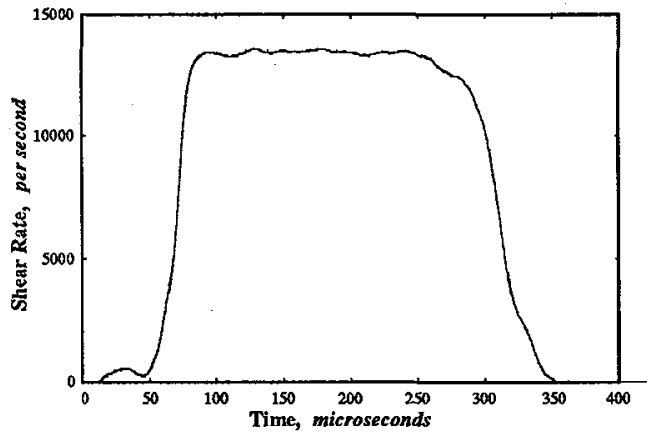

Fig.5 Typical History of the Shear Rate

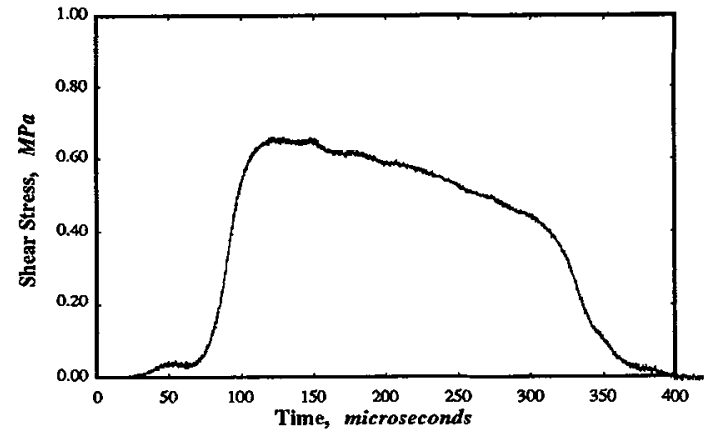

Fig. 6 Typical History of the Shear Stress

fixed initial temperature (in this case $10^{\circ} \mathrm{C}$ ). The reduction in the shearing stress is very large at the high rates; this is surprising, considering the fact that the maximum rise in temperature (computed assuming adiabatic conditions) is less than $4^{\circ} \mathrm{C}$.

In an attempt to examine the hypothesis of shear heating more closely, a numerical simulation of the experiment was performed in which the lubricant was modeled as a Newtonian fluid with a temperaturedependent viscosity:

$$
\tau=\eta_{0} \exp \left(-\beta\left(T-T_{0}\right)\right) \dot{\gamma}
$$

where $\eta_{0}$ is the viscosity and $T$ is the temperature. The temperature rise was computed by assuming that all of the viscous dissipation was converted into heat and that the process was adiabatic. Since at the early times the peak observed in the shear stress must be essentially independent of temperature, the value of $\eta_{0}$ was obtained from a plot of the maximum stress as a function of the shear rate. The value of $\beta$ required to match the decrease in the shear stress at the lowest rate was then computed; this value is two orders of magnitude larger than expected from available data on this fluid. Clearly the hypothesis of shear heating 


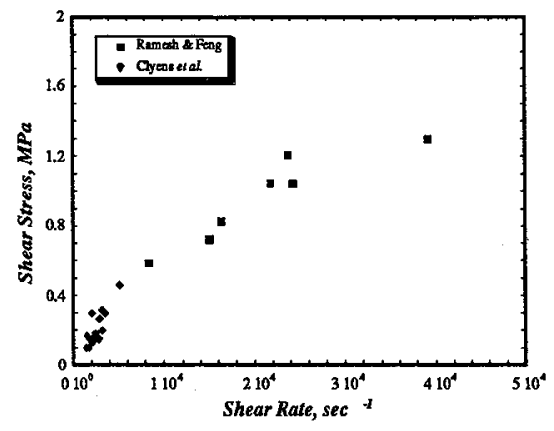

Fig. 7. Comparison with Clyens et al. (1980)

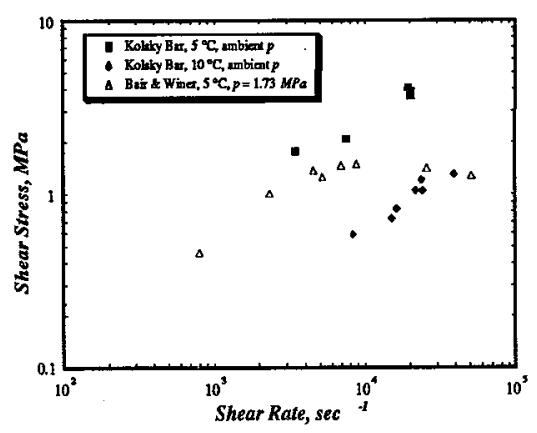

Fig. 8. Comparison with Bair \& Winer (1990)

is an untenable explanation, at least for the Newtonian fluid model.

Considering only the values of the maximum shear stresses observed during each test, and assuming that this maximum value is that corresponding to the isothermal response, we present in Fig. 7 the shear stress - shear rate behavior of the lubricant $5 \mathrm{P} 4 \mathrm{E}$ at $10^{\circ} \mathrm{C}$. Clearly there is still a definite rate-sensitivity of the flow stress, even at these high shear rates. For comparison the results of Clyens et al..$^{[5]}$ obtained on the same fluid at the same temperature using a different specimen configuration are also shown. Our results with the new specimen configuration appear to be consistent with those of the previous workers, and we are able to sustain much higher shear rates. We note that the rate dependence of the shear stress does not appear to be linear; indeed, an Eyring model would appear to be more appropriate.

Finally, we present in Fig. 8 a comparison of our results on the high-rate shearing behavior of the synthetic lubricant 5P4E at ambient pressure and at two different initial temperatures with those of Bair \& Winer ${ }^{[11]}$ obtained in a continuous rotation apparatus and under small superimposed hydrostatic pressures. The Kolsky bar results show shear stress levels sustained by the lubricant at atmospheric pressure that are significantly larger than those observed by Bair \& Winer ${ }^{[11]}$ at an imposed hydrostatic pressure of $1.73 \mathrm{MPa}$. Since the dependence of the viscosity on the pressure should be very strong, and the dependence of the "limiting shear stress" on the pressure is almost linear, the shear stresses measured in our Kolsky bar tests should have been significantly smaller than those measured in [11].

\section{Conclusions from Shearing Measurements}

- The torsional Kolsky bar technique can be used to measure the shear stress sustained by EHD lubricants under the shear rates and over timescales comparable to those within the EHD contact.

- The shear stresses sustained by the lubricants are observed to decrease with increasing time of shearing at a constant shear rate. It has been demonstrated that this softening behavior cannot be interpreted in terms of shear heating.

- The peak values of the shear stress that we observe are in agreement with the results obtained by Clyens et al.$^{[5]}$, although we are able to attain much higher shear rates. The shear stresses sustained by $5 \mathrm{P} 4 \mathrm{E}$ continue to be a strong function of shear rate even at very high shear rates.

- Even at atmospheric pressure, the peak values of the shear stress that we observe are significantly larger than observed by Bair \& Winer ${ }^{[11]}$ under superimposed hydrostatic pressure. 


\section{References}

1. Johnson, K.L., \& Cameron, R., 1968, Proc. Instn. Mech. Engrs., pg. 307, vol. 182.

2. Alsaad, M., et al., 1978a, ASME Journal of Lubrication Technology, Vol. 100, pp. 404-417.

3. Barlow, A. J., et al., 1972, Proc. Roy. Soc. Lond., Series A. 327, pp. 403-412.

4. Bair, S., \& Winer, W. O., 1979a, ASME Journal of Lubrication Technology, Vol. 101, pp. 251-257.

5. Clyens, S., et al., 1982, Proc. Roy. Soc. Lond., Series A. 381, pp. 195-214.

6. Hoglund, E., 1984, Ph.D. Dissertation, Lulea University of Technology, Lulea, Sweden.

7. Jacobson, B., 1985, ASME Journal of Tribology, Vol. 107, pp. 220-223.

8. Evans, C. R., \& Johnson, K. L., 1986, Proc. Inst. Mech. Eng., Vol. 200, No. C5, pp. 301-309.

9. Ramesh, K. T., \& Clifton, R. J., 1987, ASME Journal of Tribology, Vol. 109, pp. 215-222.

10. Ramesh, K. T., 1989, ASME Journal of Tribology, Vol. 111, pp. 614-619.

11. Bair, S., and Winer, W.O., 1990, Journal of Tribology, pg. 246, vol. 112.

12. Dowson, D., \& Higginson, G. R., 1966, Elastohydrodynamic Lubrication, Pergamon Press, Oxford.

13. Hamrock, B. J., et al., 1987, Transactions of the ASLE, Vol. 30, pg. 196.

14. Bezot, P., et al., 1986, ASME Journal of Tribology, Vol. 108, pp. 579-583.

15. Alsaad, M., et al., 1978b, ASME Journal of Lubrication Technology, Vol. 100, pp. 418-422.

16. Ramesh, K. T., 1991, ASME Journal of Tribology, Vol. 113, pp. 361-371.

17. Bair, S. \& Winer, W. O., 1991, in Discussion of [16], ASME Journal of Tribology, Vol. 113, pg. 370. 